\title{
Doppler tissue imaging for assessing left ventricular diastolic dysfunction in heart transplant rejection
}

\author{
S-M Stengel, Y Allemann, M Zimmerli, E Lipp, N Kucher, P Mohacsi, C Seiler
}

\begin{abstract}
Objective-To test the hypothesis that diastolic mitral annular motion velocity, as determined by Doppler tissue imaging and left ventricular diastolic flow propagation velocity, is related to the histological degree of heart transplant rejection according to the International Society of Heart and Lung Transplantation (ISHLT).

Methods-In 41 heart transplant recipients undergoing 151 myocardial biopsies, the following Doppler echocardiographic measurements were performed within one hour of biopsy: transmitral and pulmonary vein flow indices; mitral annular motion velocity indices; left ventricular diastolic flow propagation velocity.

Results-Late diastolic mitral annular motion velocity $\left(\mathrm{A}_{\mathrm{DTI}}\right)$ and mitral annular systolic contraction velocity $\left(\mathrm{SC}_{\mathrm{DTI}}\right)$ were higher in patients with ISHLT $<$ IIIA than in those with ISHLT $\geqslant$ IIIA $\left(\mathrm{A}_{\mathrm{DTI}}, 8.8 \mathrm{~cm} / \mathrm{s} v 7.7 \mathrm{~cm} / \mathrm{s}(\mathrm{p}=0.03) ; \mathrm{SC}_{\mathrm{DTI}}, 19.3 \mathrm{~cm} / \mathrm{s} v 9.3 \mathrm{~cm} / \mathrm{s}(\mathrm{p}<0.05)\right)$. Sensitivity and specificity of $\mathrm{A}_{\mathrm{DTI}}<8.7 \mathrm{~cm} / \mathrm{s}$ (the best cut off value) in predicting significant heart transplant rejection were $82 \%$ and $53 \%$, respectively. Early diastolic mitral annular motion velocity $\left(\mathrm{E}_{\mathrm{DTI}}\right)$ and flow propagation velocity were not related to the histological degree of heart transplant rejection.

Conclusions-Doppler tissue imaging of the mitral annulus is useful in diagnosing heart transplant rejection because a high late diastolic mitral annular motion velocity can reliably exclude severe rejection. However, a reduced late diastolic mitral annular motion velocity cannot predict severe rejection reliably because it is not specific enough.

(Heart 2001;86:432-437)
\end{abstract}

Keywords: heart transplant rejection; diastolic function; Doppler tissue imaging; echocardiography

Within the past 20 years, cardiac transplantation has evolved from an experimental surgical procedure to standard care for patients with end stage heart failure. Although there have been significant advances in surgical techniques, in donor and recipient selection criteria, and in the management of transplant patients, allograft rejection remains the primary cause of morbidity in this group of patients. ${ }^{1}$ As acute rejection is initially asymptomatic, regular rejection surveillance is obligatory. For detecting allograft rejection and monitoring immunosuppressive treatment, clinical and laboratory examinations along with endomyocardial biopsies are conducted following a predetermined time schedule.

Endomyocardial biopsy still represents the gold standard for the detection of acute allograft rejection. Though it has been suggested that various non-invasive methodsincluding sensitive ECG indices, ${ }^{2}$ echocardiographic measurements, ${ }^{34}$ phosphorus-31 nuclear magnetic resonance spectroscopy, ${ }^{5}$ gamma scintigraphy, ${ }^{6}$ and serological ${ }^{7}$ and immunological $^{8}$ tests-could replace endomyocardial biopsy, these techniques have not been proven to be clinically useful.

Doppler tissue imaging and left ventricular diastolic flow propagation velocity measurements are new Doppler techniques for assessing left ventricular diastolic function. Selective measurements of tissue contraction and relaxation velocities at the mitral annulus ${ }^{9}$ can detect left ventricular dysfunction more accurately than conventional echocardiography. ${ }^{10}{ }^{11}$ As left ventricular diastolic dysfunction is an early event during allograft rejection, these techniques may be useful for detecting rejection non-invasively.

Our purpose in this study was to apply these new Doppler techniques to a cardiac transplant population and to assess their reliability in detecting endomyocardial biopsy proven acute allograft rejection.

\section{Methods}

STUDY POPULATION

Forty one consecutive adult orthotopic heart transplant recipients (mean (SD) age 53 (13) years; 35 men, six women), referred for routine examination, were included in a prospective study. All the patients were examined for transplant rejection by myocardial biopsy and Doppler echocardiography. The biopsy material was considered adequate in all cases and all the echocardiographic examinations were readable. In all, 151 biopsies and Doppler echocardiographic examinations, including Doppler tissue imaging, were performed. All patients gave their informed consent for their participation in the study, which was approved by the local ethics committee.

ENDOMYOCARDIAL BIOPSY

For monitoring transplant rejection, serial right ventricular endomyocardial biopsies were taken through the right jugular vein. In the first month after transplantation, an endomyocardial biopsy was taken weekly; in the second 
month, once every two weeks; from the third to the sixth month, once every four weeks; and from the seventh to the 12 th month, once every eight weeks. In the second year, an endomyocardial biopsy was taken once every three months, and from the third year on, once every six to 12 months. If required, additional biopsies were taken.

Cellular rejection was determined using the International Society of Heart and Lung Transplantation (ISHLT) criteria $^{12}$ : grade $0=$ no rejection; grade IA = focal (perivascular or interstitial) infiltrate without myocyte damage; grade IB = diffuse but sparse infiltrate without myocyte damage; grade II = one focus only with aggressive infiltrates and/or myocyte damage; grade IIIA = multifocal aggressive infiltrates and/or myocyte damage; grade IIIB =

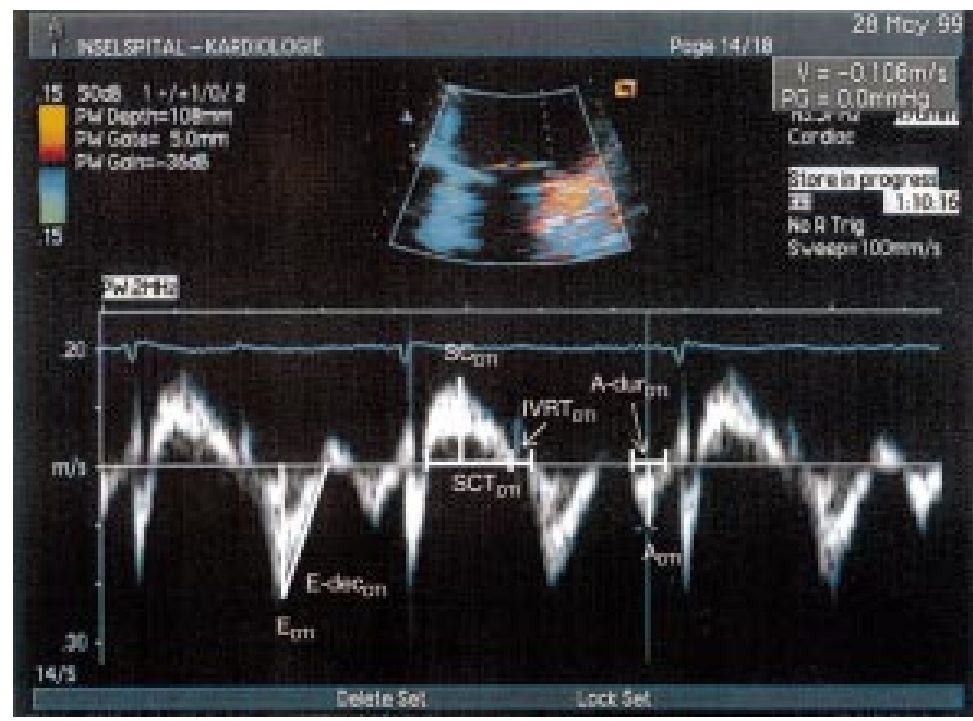

Figure 1 Doppler tissue imaging derived mitral annular motion velocity profiles obtained from the apical two chamber view from a heart transplant recipient. The following diastolic annular motion variables were measured: early $\left(E_{D T}\right)$ and late $\left(A_{D T D}\right)$ diastolic mitral annular motion velocity; deceleration time of $E_{D T I}\left(E-d e c_{D T}\right)$; duration of late mitral annular motion velocity $\left(A-d u r_{D T}\right)$; mitral annular isovolumetric relaxation time (IVRT $\left.T_{D T}\right)$; mitral annular systolic contraction velocity $\left(S C_{D T}\right)$; and mitral annular systolic contraction time $\left(S C T_{D T}\right)$.

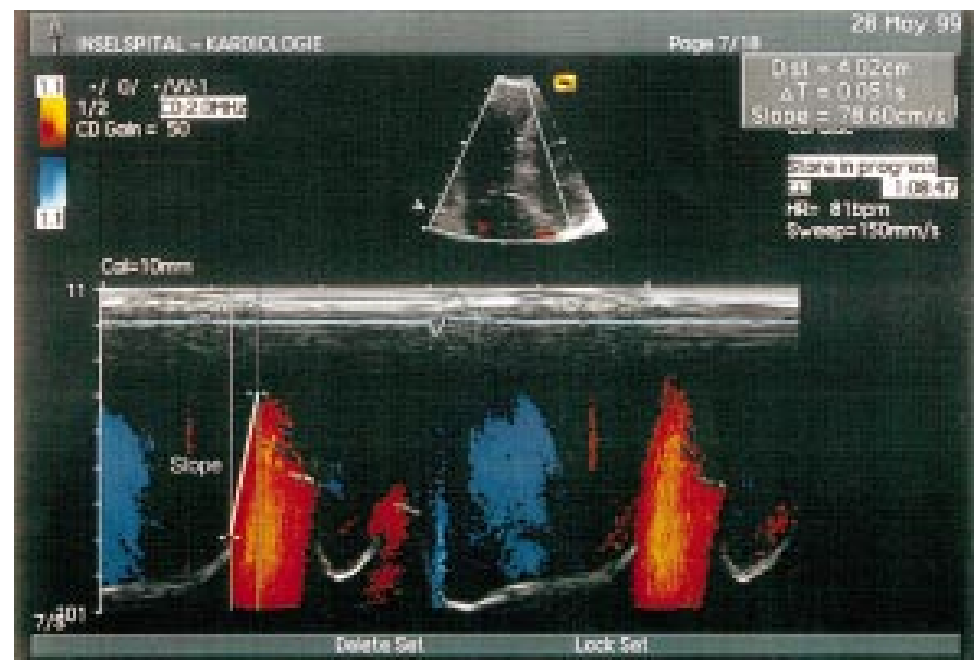

Figure 2 Measurement from colour Doppler $M$ mode of left ventricular diastolic flow propagation velocity, which is determined by the slope of the first aliasing isovelocity line during early ventricular filling. The velocity is assessed from the apical four chamber viezu at $4 \mathrm{~cm}$ distal to the mitral valve plane $(0.051 \mathrm{~s}$ for $4.02 \mathrm{~cm}$ is equal to a flow propagation velocity of $78.6 \mathrm{~cm} / \mathrm{s}$ ). diffuse inflammatory process with myocyte necrosis; grade IV = diffuse aggressive polymorphous infiltrate with haemorrhage and myocyte necrosis. Severe rejection was defined at ISHLT $\geqslant$ IIIA. ${ }^{13}{ }^{14}$ Histological analyses were graded by an experienced pathologist blinded to the Doppler echocardiographic findings.

The study population was subdivided in two groups according to the degree of rejection: ISHLT < IIIA and ISHLT $\geqslant$ IIIA. Accordingly, a patient could be in both groups depending on the degree of rejection at the time of a particular endomyocardial biopsy.

DOPPLER ECHOCARDIOGRAPHY

Doppler echocardiography, including Doppler tissue imaging, was performed within one hour of endomyocardial biopsy. Patients underwent conventional transthoracic $M$ mode cross sectional echocardiography, as well as Doppler examination, using an Acuson Sequoia C256 ultrasonography system (Acuson Inc, Mountain View, California, USA). This was equipped with $2.5-5.0 \mathrm{MHz}$ phased array cross sectional transducers, second harmonic imaging, and Doppler tissue imaging software.

All measurements were performed in the supine left lateral position, according to the recommendations of the American Society of Echocardiography. ${ }^{15}$

Left ventricular $M$ mode measurements $(\mathrm{mm})$ included septal wall thickness and posterior wall thickness at end diastole, and left ventricular internal diameter at end diastole and end systole. From the diastolic measurements, left ventricular mass index $\left(\mathrm{g} / \mathrm{m}^{2}\right)$ was calculated, using the cube formula. ${ }^{16}$ Apical two and four chamber views were acquired. Left ventricular volume measurements for the calculation of ejection fraction (\%) were performed as recommended by the American Society of Echocardiography. ${ }^{17}$ The transthoracic examination also included spectral pulsed wave Doppler analysis of transmitral flow velocity, obtained at the tips of the mitral valve leaflets. The following transmitral Doppler variables were obtained: early diastolic flow velocity $(\mathrm{E}, \mathrm{cm} / \mathrm{s})$, late diastolic flow velocity (A, $\mathrm{cm} / \mathrm{s}), \mathrm{E}: \mathrm{A}$ ratio, deceleration time of early transmitral filling (E-dec, $\mathrm{ms}$ ), isovolumetric relaxation time (IVRT, $\mathrm{ms}$ ), and the duration of late diastolic flow velocity (A-dur, ms).

Examination of the pulmonary veins was performed using pulsed wave Doppler. The sample volume was positioned approximately $1 \mathrm{~cm}$ within the right upper pulmonary vein. Measurements in the apical four chamber view included systolic and diastolic peak flow velocities $(\mathrm{cm} / \mathrm{s})$ and their ratio, flow velocity at atrial contraction (A wave, $\mathrm{cm} / \mathrm{s}$ ), and A wave duration (ms).

Doppler tissue imaging is a modification of the conventional Doppler technology. Using filtering algorithms, tissue derived slow motion Doppler signals $(\leqslant 15 \mathrm{~cm} / \mathrm{s})$ can be discriminated from blood flow velocity signals which are of much lower intensity in a comparable velocity range. Tissue derived Doppler signals 
Table 1 Patient characteristics

\begin{tabular}{llll}
\hline & ISHLT < IIIA & ISHLT $\geqslant$ IIIA & p Value \\
\hline Number of patients & 25 & 16 & \\
Number of EMB & 128 & 23 & \\
Number of EMB/patient & 5.1 & 1.4 & \\
Mean age (years) & 54 & 50 & NS \\
Male & 22 & 13 & NS \\
Female & 3 & 3 & \\
Body surface area $\left(\mathrm{m}^{2}\right)$ & $1.86(0.15)$ & $1.77(0.2)$ & 0.02 \\
Follow up after heart transplant (days) & $466(525)$ & $449(587)$ & NS \\
Reason for heart transplant & & & \\
$\quad$ CAD & 12 & 8 & NS \\
DCMP & 4 & 1 & NS \\
$\quad$ VHD & 6 & 2 & NS \\
$\quad$ Others & $131(25)$ & $120(16)$ & NS \\
Systolic blood pressure (mm Hg) & $80(16)$ & $75(11)$ & NS \\
Diastolic blood pressure (mm Hg) & $90(19)$ & $97(25)$ & NS \\
Heart rate (beats/min) & & & \\
\hline
\end{tabular}

Values are $\mathrm{n}$ or mean $(\mathrm{SD})$

CAD, coronary artery disease; DCMP, dilatated cardiomyopathy; EMB, endomyocardial biopsy; ISHLT, International Society of Heart and Lung Transplantation; VHD, valvar heart disease.

can be displayed either as time-velocity tracings or as cross sectional or $\mathrm{M}$ mode colour images. ${ }^{1018-20}$

Mitral annular Doppler tissue imaging measurements were performed from the apical four and two chamber views at the lateral, inferior, and anterior site. Because septal wall motion and contraction in transplanted hearts is often paradoxical, delayed, or hypokinetic, we did not consider this site in our analysis.

The Doppler tissue imaging program was set to the pulsed wave Doppler mode. The Nyquist limit was adjusted to a velocity range of -16 to $20 \mathrm{~cm} / \mathrm{s}$. Gain was minimised to allow for a clear tissue signal with minimum background noise. Sweep rate was set at $100 \mathrm{~mm} / \mathrm{s}$. From the apical four chamber view a $2 \mathrm{~mm}$ sample volume was placed at the lateral corner of the mitral annulus. From the apical two chamber view, the sample volume was placed at the anterior and inferior corner of the mitral annulus. Mitral annular Doppler tissue imaging measurements (fig 1) were recorded on VHS videotape for off line analysis. These included early $\left(\mathrm{E}_{\mathrm{DTI}}, \mathrm{cm} / \mathrm{s}\right)$ and late diastolic mitral annular motion velocity $\left(\mathrm{A}_{\mathrm{DTI}}, \mathrm{cm} / \mathrm{s}\right)$, $\mathrm{E}_{\mathrm{DTI}}: \mathrm{A}_{\mathrm{DTI}}$ ratio, the deceleration time of early diastolic mitral annular motion velocity (E$\left.\mathrm{dec}_{\mathrm{DTI}}, \mathrm{ms}\right)$, the duration of late mitral annular

Table 2 Doppler echocardiographic indices motion velocity (A-dur $\left.{ }_{\mathrm{DTI}}, \mathrm{ms}\right)$, mitral annular isovolumetric relaxation time $\left(\right.$ IVRT $_{\text {DTI }}, \mathrm{ms}$ ), mitral annular systolic contraction velocity $\left(\mathrm{SC}_{\mathrm{DTI}}, \mathrm{cm} / \mathrm{s}\right)$, and mitral annular systolic contraction time $\left(\mathrm{SCT}_{\mathrm{DTI}}, \mathrm{ms}\right)$. All analysed variables were obtained at the lateral, inferior, and anterior site of the mitral annulus and averaged. Each measurement at a given site was performed over three consecutive cardiac cycles and these results were also averaged.

Interobserver variability (between observers $\mathrm{x}$ and $\mathrm{y}$ ) for $\mathrm{E}_{\mathrm{DTI}}$ and $\mathrm{A}_{\mathrm{DTI}}$ was as follows:

$\mathrm{E}_{\mathrm{DTI}}: \mathrm{y}=0.048+0.809^{\star} \mathrm{x} ; r=0.75, \mathrm{p}<0.0001$, $\mathrm{n}=138, \mathrm{SEE}_{\mathrm{EDTI}}=2.0 \mathrm{~cm} / \mathrm{s}$;

$A_{D T I}: \mathrm{y}=0.026+0.691^{\star} \mathrm{x} ; r=0.81, \mathrm{p}<0.0001$, $\mathrm{n}=136, \mathrm{SEE}_{\mathrm{ADTI}}=1.2 \mathrm{~cm} / \mathrm{s}$.

Left ventricular diastolic flow propagation velocity was determined using colour Doppler $M$ mode obtained from the apical four chamber view. It was determined as the slope of the first aliasing isovelocity line during early ventricular filling. The slope was assessed $4 \mathrm{~cm}$ distal to the mitral valve plane (fig 2). ${ }^{21}$ All Doppler echocardiographic measurements were performed by two echocardiographers blinded to the histopathological findings.

STATISTICAL ANALYSES

Values are given as mean (SD). Between-group comparisons of continuous demographic, echocardiographic, and Doppler flow velocity data were performed by the unpaired Student $t$ test. Between-group comparisons of categorical data were analysed using a $\chi^{2}$ test. Linear regression analysis was applied for analysis of an association between continuous ISHLT values and Doppler echocardiographic indices, and for interobserver variability of Doppler tissue imaging measurements.

For determining the accuracy of Doppler echocardiographic indices in detecting severe rejection, receiver operating characteristic (ROC) analysis was performed at a cut off value of ISHLT $<$ III A or $\geqslant$ III A. A probability value of $p<0.05$ was considered significant.

\begin{tabular}{|c|c|c|c|}
\hline & $I S H L T<I I I A$ & $I S H L T \geqslant I I I A$ & $p$ Value \\
\hline \multicolumn{4}{|l|}{ M Mode measurements } \\
\hline Septal wall thickness, ED (mm) & $13.9(2.8)$ & $14.8(3.2)$ & NS \\
\hline Posterior wall thickness, ED (mm) & $13.2(3.3)$ & $13.2(3.7)$ & NS \\
\hline LV internal diameter, $\mathrm{ED}(\mathrm{mm})$ & $42.6(6.0)$ & $39.9(6.8)$ & NS \\
\hline LV internal diameter, $\mathrm{ES}(\mathrm{mm})$ & $29.2(5.6)$ & $28.5(6.4)$ & NS \\
\hline $\mathrm{LV}$ mass index $\left(\mathrm{g} / \mathrm{m}^{2}\right)$ & $119(32)$ & $117(28)$ & NS \\
\hline LV ejection fraction (\%) & $58(14)$ & $55(13)$ & NS \\
\hline \multicolumn{4}{|l|}{ Transmitral Doppler data } \\
\hline Early diastolic flow velocity (E) (m/s) & $0.84(0.23)$ & $0.82(0.24)$ & NS \\
\hline Late diastolic flow velocity (A) (m/s) & $0.44(0.15)$ & $0.44(0.15)$ & NS \\
\hline $\mathrm{E}:$ A ratio & $2.02(0.68)$ & $2.05(0.84)$ & NS \\
\hline Deceleration time of early transmitral filling (E-dec) (ms) & $134(39)$ & $129(41)$ & NS \\
\hline Isovolumetric relaxation time $(\mathrm{ms})$ & $90(25)$ & $88(36)$ & NS \\
\hline Duration of late diastolic flow velocity (A-dur) (ms) & $120(27)$ & $126(37)$ & NS \\
\hline \multicolumn{4}{|l|}{ Pulmonary vein flow indices } \\
\hline Systolic peak flow velocity $(\mathrm{m} / \mathrm{s})$ & $0.33(0.11)$ & $0.32(0.15)$ & NS \\
\hline Diastolic peak flow velocity $(\mathrm{m} / \mathrm{s})$ & $0.64(0.18)$ & $0.63(0.11)$ & NS \\
\hline Ratio systolic/diastolic peak flow velocity & $0.54(0.21)$ & $0.51(0.24)$ & NS \\
\hline Flow velocity of atrial contraction $(\mathrm{A}, \mathrm{m} / \mathrm{s})$ & $0.23(0.06)$ & $0.23(0.07)$ & NS \\
\hline Duration of late diastolic flow velocity (A-dur, ms) & $160(41)$ & $157(31)$ & NS \\
\hline
\end{tabular}

Values are mean (SD).

ED, end diastolic; ES, end systolic; ISHLT, International Society of Heart and Lung Transplantation; LV, left ventricle. 
Table 3 Doppler tissue imaging: mitral annular motion velocity data

\begin{tabular}{|c|c|c|c|}
\hline & $I S H L T<I I I A$ & $I S H L T \geqslant I I I A$ & $p$ Value \\
\hline Early diastolic mitral annular motion velocity $\left(\mathrm{E}_{\mathrm{DTI}}\right)(\mathrm{cm} / \mathrm{s})$ & $12.7(3.2)$ & $11.5(2.5)$ & 0.09 \\
\hline Late diastolic mitral annular motion velocity $\left(\mathrm{A}_{\mathrm{DTI}}\right)(\mathrm{cm} / \mathrm{s})$ & $8.8(2.4)$ & $7.7(1.8)$ & 0.03 \\
\hline $\mathrm{E}_{\mathrm{DTI}} / \mathrm{A}_{\mathrm{DTI}}$ & $1.76(0.48)$ & $1.82(0.44)$ & NS \\
\hline Deceleration time of early diastolic motion velocity $\left(\mathrm{E}-\mathrm{dec}_{\mathrm{DTI}}\right)(\mathrm{ms})$ & $78(18)$ & $74(18)$ & NS \\
\hline Duration of late mitral annular motion velocity (A-dur $\left.{ }_{\text {DTT }}\right)(\mathrm{ms})$ & $95(20)$ & $95(16)$ & NS \\
\hline Mitral annular isovolmetric relaxation time $\left(\right.$ IVRT $\left._{\mathrm{DTI}}\right)(\mathrm{ms})$ & $116(27)$ & $110(35)$ & NS \\
\hline Mitral annular systolic contraction velocity $\left(\mathrm{SC}_{\mathrm{DTI}}\right)(\mathrm{cm} / \mathrm{s})$ & $10.3(2.2)$ & $9.3(1.7)$ & $<0.05$ \\
\hline Mitral annular systolic contraction time $\left(\mathrm{SCT}_{\mathrm{DTI}}\right)(\mathrm{ms})$ & $229(31)$ & $223(36)$ & NS \\
\hline LV diastolic flow propagation velocity (slope) $(\mathrm{cm} / \mathrm{s})$ & $70.5(33.8)$ & $78.5(49.7)$ & NS \\
\hline
\end{tabular}

Values are mean $(\mathrm{SD})$.

DTI, Doppler tissue imaging; ISHLT, International Society of Heart and Lung Transplantation; LV, left ventricle.

\section{Results}

PATIENT CHARACTERISTICS AND CLINICAL DATA In all, 151 endomyocardial biopsies were obtained, ranging from 1-12 per patient (table 1). In 25 patients (with a total of 128 examinations), ISHLT was < IIIA; in 16 patients (23 examinations), ISHLT was $\geqslant$ IIIA.

Endomyocardial histopathology revealed ISHLT rejection grade 0 in 73 samples, grade IA in 30 , grade IB in 22, grade II in 3, and grade IIIA in 23. The highest biopsy score obtained during the four month study period was IIIA. The patients' regular immunosuppression regimen included cyclosporin, azathioprine and prednisone or cyclosporin, and mycophenolat and prednisone. All patients were in New York Heart Association functional class 0 or I.

There was no significant difference between the groups for age, sex, time between heart transplantation and follow up examination, reasons for heart transplantation, blood pressure, or heart rate (table 1). Body surface area was significantly larger in patients without than with severe rejection (ISHLT $\geqslant$ IIIA).

DOPPLER ECHOCARDIOGRAPHIC INDICES

M mode measurements, transmitral Doppler flow velocity data, and pulmonary vein flow indices (table 2) showed no significant difference between patients without (ISHLT < IIIA) and with severe transplant rejection (ISHLT $\geqslant$ IIIA).

MITRAL ANNULAR MOTION VELOCITY DATA

Both late diastolic mitral annular motion velocity $\left(\mathrm{A}_{\mathrm{DTI}}\right)$ and mitral annular systolic contraction velocity $\left(\mathrm{SC}_{\mathrm{DTI}}\right)$ were significantly higher in the group without than with severe rejection (table 3). All other mitral annular motion velocity indices, as well as left ventricular diastolic flow propagation velocity, were similar between the study groups (table 3 ).

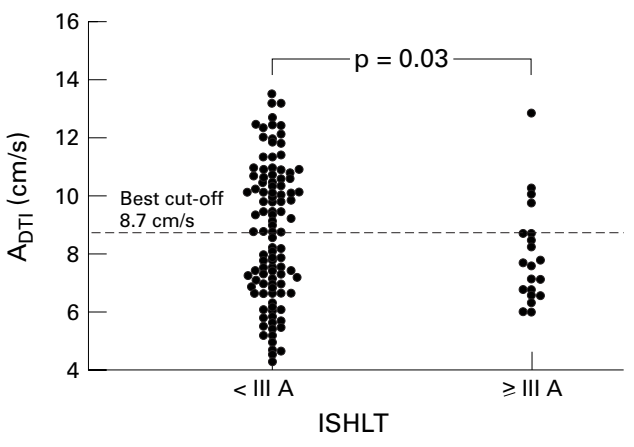

Figure 3 Changes in late diastolic mitral annular motion velocity $\left(A_{D T D}, \mathrm{~cm} / \mathrm{s}\right.$, vertical axis) among patients without (ISHLT < IIIA) and with (ISHLT $\geqslant$ IIIA) severe heart transplant rejection. $A_{D T I} \geqslant 8.7 \mathrm{~cm} / \mathrm{s}$ can reliably exclude severe heart transplant rejection, but a reduced $A_{D T I}$ cannot predict severe rejection.

$A_{\text {DTI }}$ was linearly and inversely correlated with the severity of rejection, whereas the other mitral annular motion velocity variables and left ventricular diastolic flow propagation did not show an association with the histological degree of rejection (table 4).

According to ROC analysis, $\mathrm{A}_{\mathrm{DTI}}<8.7 \mathrm{~cm} / \mathrm{s}$ predicted severe rejection (ISHLT $\geqslant$ IIIA) with a sensitivity of $82 \%$ and a specificity of $53 \%$ (fig 3). The area under the ROC curve was 0.65 .

\section{Discussion}

As heart transplantation is a standard form of care for patients with end stage heart disease, organ rejection is a major clinical problem, and the patient's immune response has to be suppressed permanently. To optimise medical immunosuppressive treatment, allograft rejection needs to be detected at an early stage. So far, endomyocardial biopsy has been and is the gold standard, though many clinical approaches have been undertaken to find a less invasive method with sufficient accuracy to detect allograft rejection.

Table 4 Doppler tissue imaging: association between mitral annular motion velocity and flow propagation variables versus ISHLT values for assessing heart transplant rejection

\begin{tabular}{|c|c|c|c|c|}
\hline & $y$ Intercept & Slope & $r$ & $p$ Value \\
\hline Early diastolic mitral annular motion velocity $\left(\mathrm{E}_{\mathrm{DTI}}\right)(\mathrm{cm} / \mathrm{s})$ & 14.6 & -0.003 & -0.095 & NS \\
\hline Late diastolic mitral annular motion velocity $\left(\mathrm{A}_{\mathrm{DTT}}\right)(\mathrm{cm} / \mathrm{s})$ & 9 & -0.004 & -0.178 & 0.03 \\
\hline $\mathrm{E}_{\mathrm{DTI}} / \mathrm{A}_{\mathrm{DTI}}$ & 1.75 & 0.02 & 0.045 & NS \\
\hline Deceleration time of early diastolic motion velocity $\left(\mathrm{E}-\mathrm{dec}_{\mathrm{DTI}}\right)(\mathrm{ms})$ & 78.4 & -1.55 & -0.095 & NS \\
\hline Duration of late mitral annular motion velocity $\left(\mathrm{A}-\right.$-dur $\left._{\mathrm{DTI}}\right)(\mathrm{ms})$ & 96.1 & -1.12 & -0.063 & NS \\
\hline Mitral annular isovolumetric relaxation time $\left(\right.$ IVRT $\left._{\text {DTI }}\right)(\mathrm{ms})$ & 114 & 0.83 & 0.031 & NS \\
\hline Mitral annular systolic contraction velocity $\left(\mathrm{SC}_{\mathrm{DTI}}\right)(\mathrm{cm} / \mathrm{s})$ & 153.5 & -2.83 & -0.105 & NS \\
\hline Mitral annular systolic contraction time $\left(\mathrm{SCT}_{\mathrm{DTI}}\right)(\mathrm{ms})$ & 232.1 & -3.98 & -0.136 & NS \\
\hline LV diastolic flow propagation velocity (slope) $(\mathrm{cm} / \mathrm{s})$ & 69 & 3.01 & 0.088 & NS \\
\hline
\end{tabular}

DTI, Doppler tissue imaging; ISHLT, International Society of Heart and Lung Transplantation; LV, left ventricle. 
Changes in myocardial structure caused by rejection induced oedema, lymphocyte infiltration, increased mass, and myocardial necrosis ${ }^{22}$ have been shown to compromise myocyte function, resulting in increased myocardial stiffness and abnormal relaxation. ${ }^{23}$ Doppler tissue imaging, a non-invasive ultrasound procedure, is capable of selectively measuring the low velocity, high amplitude Doppler signals reflected by moving myocardium, while filtering out the high velocity, low amplitude signals emitted by moving blood cells. ${ }^{20}$ Doppler tissue imaging is an accurate method of detecting diastolic dysfunction, ${ }^{10}{ }^{18}$ a condition that is known to be an early manifestation of rejection. ${ }^{24}$ However, in the present study-which included more than 150 endomyocardial biopsies among 41 heart transplant recipients-late diastolic mitral annular motion velocity analysis proved to be only moderately reliable in detecting severe allograft rejection. Neither early diastolic mitral annular motion velocity nor flow propagation velocity obtained during early left ventricular filling was associated with the degree of transplant rejection.

TRADITIONALLY EMPLOYED ECHOCARDIOGRAPHIC METHODS FOR DETECTING HEART TRANSPLANT REJECTION

There are several reasons why conventionally employed echocardiographic measurement variables have notoriously low sensitivity for detecting acute rejection. ${ }^{3}$ Wall thickness and left ventricular mass determinations are rather crude measurements which are influenced by operator dependent errors in performing $M$ mode echocardiography. Pathophysiologically, rejection induced myocardial oedema manifested by an echocardiographically discernible increase in wall thickness is a rather late event. However, enhanced sensitivity of echocardiography for detecting rejection would require the ability to assess early rather than late cardiac alterations. Documenting the latter only enhances the specificity of the method.

In principle, the assessment of left ventricular diastolic function by Doppler echocardiography should allow the sensitive detection of acute rejection, as impaired left ventricular filling caused by myocardial lymphocyte infiltration and oedema occurs much earlier than increased myocardial wall thickness. ${ }^{24}{ }^{25}$ However, Doppler transmitral and pulmonary venous flow velocity analyses have not upheld their promise in detecting rejection related diastolic dysfunction, for two main reasons. First, transmitral Doppler flow indices are influenced by variables other than ventricular diastolic function, such as age, heart rate, and most importantly ventricular loading conditions ${ }^{26}$; pulmonary venous flow velocity indices are particularly variable, even in individuals without heart disease. ${ }^{27}$ Second, denervation of the transplanted heart, with its lack of autonomous regulation and invariable tachycardia, leads to a form of restrictive ventricular filling pattern that amounts to diastolic dysfunction in the absence of acute rejection. ${ }^{28}$ The lack of any statistical difference between our two study groups in the traditionally employed Doppler echocardiographic indices is further confirmation of these drawbacks.

MITRAL ANNULAR MOTION VELOCITY TO DISCERN HEART TRANSPLANT REJECTION

The main finding of our study - that is, the rather poor specificity of "new" Doppler techniques in detecting severe rejection-is in agreement with other recently published studies that have used a similar study design to ours. For example, Derumeaux and colleagues found values for sensitivity and specificity of $92 \%$ using early diastolic mitral annular motion velocity during mild or moderate and severe rejection, in comparison with a healthy group. ${ }^{29}$ With increasing rejection grade, early diastolic wall motion velocities decreased significantly $(\mathrm{p}>0.001)$. Puleo and associates tested 121 heart transplant recipients who underwent Doppler tissue imaging at the time of surveillance endomyocardial biopsy. ${ }^{23}$ These investigators found a decrease in the peak velocity of $\mathrm{E}_{\mathrm{DTI}}$ at the inferior wall during moderate allograft rejection $(0.14 \quad(0.01) \mathrm{m} / \mathrm{s}$; $\mathrm{p}<0.0001)$ and no change in peak systolic velocity $(0.08(0.02) \mathrm{m} / \mathrm{s} ; \mathrm{NS})$ in comparison with non-rejecting allograft recipients, with a sensitivity of $76 \%$ and a specificity of $88 \%$. In 78 transplant recipients (among whom 75 histological analyses revealed no significant rejection), Mankad and colleagues found a reduction in posterior wall peak systolic and diastolic velocity gradients with rejection $(\mathrm{p}<0.05 v$ non-rejecting group), as well as a reduction in peak systolic $\left(\mathrm{SC}_{\mathrm{DTI}}\right)$ and diastolic $\left(\mathrm{E}_{\mathrm{DTI}}\right)$ mitral annular motion velocities ( $\mathrm{p}>0.001 v$ nonrejecting group), with a sensitivity of $93 \%$ and a specificity of $71 \% .{ }^{30}$

Certain discrepancies between these study findings and ours may have a methodological and technical basis. Pathologically, there was a lack of grade IV rejection and a relatively small number of cases of grade III or more in our study, compared with the studies cited above. This probably impaired the statistical ability to sense a severely blunted mitral annular velocity during diastole. Interobserver variability in off line analysis of Doppler tissue imaging variables was greater in our study than in others, ${ }^{27}$ and this may also have hampered the ability of late diastolic annular motion measurements to predict rejection. Both these problems could explain why in our study early diastolic mitral annular motion velocity only showed a trend towards lower values during episodes of rejection, whereas it was significantly lower in the investigations cited above. ${ }^{23} 2930$

The fact that the best threshold of late diastolic mitral annular motion velocity (below $9 \mathrm{~cm} / \mathrm{s}$ ) falsely detected rejection in almost $50 \%$ of cases also indicates that the pathophysiological problem of transplant related restriction to left ventricular filling impairs the reliability of any tool assessing diastolic function during the early rejection process.

CLINICAL IMPLICATIONS AND CONCLUSION Diastolic mitral annular motion velocity measurements using Doppler tissue imaging should be employed routinely in the surveillance of 
heart transplant rejection. However, their value consists in reliably detecting patients not suffering from acute transplant rejection rather than in specifically detecting those with rejection. Thus in patients with a late diastolic annular motion velocity above $9 \mathrm{~cm} / \mathrm{s}$ it may be reasonably safe not to undertake endomyocardial biopsy at any particular point during rejection surveillance.

1 Stevenson LW, Miller LW. Cardiac transplantation as therapy for heart failure. Curr Probl Cardiol 1991;16:217305 .

2 Izrailtyan I, Kresh JY, Morris RJ, et al. Early detection of acute allograft rejection by linear and nonlinear analysis of heart rate variability. F Thorac Cardiovasc Surg 2000;120 $737-45$.

3 Dodd DA, Brady LD, Carden KA, et al. Pattern of echocardiographic abnormalities with acute cardiac allograft rejection in adults: correlation with endomyocardial biopsy. $\mathcal{F}$ Heart Lung Transplant 1993;12:1009-17.

4 Valantine HA, Yeoh TK, Gibbons R, et al. Sensitivity and specificity of diastolic indexes for rejection surveillance: specificity of diastolic indexes for rejection surveillance: Lung Transplant 1991;10:757-65.

5 Van Dobbenburgh JO, De Groot MC, De Jonge N, et al. Myocardial high-energy phosphate metabolism in heart transplant patients is temporarily altered irrespective of rejection. NMR Biomed 1999;12:515-24

6 Rubin PJ, Hartman JJ, Hasapes JP, et al. Detection of cardiac transplant rejection with ${ }^{111}$ In-labeled lymphocytes and gamma scintigraphy. Circulation 1996;94:II-298-303.

7 Dengler TJ, Zimmermann R, Braun K, et al. Elevated serum concentrations of cardiac troponin $\mathrm{T}$ in acute allograft rejection after human heart transplantation. $\mathcal{f} \mathrm{Am}$ Coll Cardiol 1998;32:405-12.

8 Ballester M, Bordes R, Tazelaar HD, et al. Evaluation of biopsy classification for rejection: relation to detection of myocardial damage by monoclonal antimyosin antibody imaging. 7 Am Coll Cardiol 1998;31:1357-61.

9 Rodriguez L, Garcia M, Ares M, et al. Assessment of mitral annular dynamics during diastole by Doppler tissue imaging: comparison with mitral Doppler inflow in subjects without heart disease and in patients with left ventricular hypertrophy. Am Heart $\mathcal{F}$ 1996;131:982-7.

10 Sutherland GR, Stewart MJ, Groundstroem KW, et al. Color Doppler myocardial imaging: a new technique for the assessment of myocardial function. $\mathcal{F} \mathrm{Am}$ Soc Echocardiogr 1994;7:441-58

11 Palka P, Lange A, Fleming AD, et al. Doppler tissue imaging: myocardial wall motion velocities in normal subjects. F Am Soc Echocardiogr 1995;8:659-68.

12 Billingham ME, Cary NR, Hammond ME, et al. A working formulation for the standardization of nomenclature in the. f Heart Transplant 1990;9:587-93.

13 DeNofrio D, Rho R, Morales FJ, et al. Detection of anti-HLA antibody by flow cytometry in patients with a left ventricular assist device is associated with early rejection following heart transplantation. Transplantation 2000;69: 814-18.

14 Yamani MH, Starling RC, Goormastic M, et al. The impact of routine mycophenolate mofetil drug monitoring on the treatment of cardiac allograft rejection. Transplantation 2000;69:2326-30.

15 Sahn DJ, DeMaria A, Kisslo J, et al. Recommendations regarding quantitation in M-mode echocardiography: results of a survey of echocardiographic measurements. Circulation 1978;58:1072-83.

16 Troy BL, Pombo J, Rackley CE. Measurement of left ventricular wall thickness and mass by echocardiography. Circulation 1972;45:602-11.

17 Schiller NB, Shah PM, Crawford M, et al. Recommendations for quantitation of the left ventricle by twodimensional echocardiography. American Society of Echocardiography Committee on Standards, subcommittee on quantitation of two-dimensional echocardiograms. $\mathcal{f} \mathrm{Am}$ Soc Echocardiogr 1989;2:358-67.

18 Sohn DW, Chai IH, Lee DJ, et al. Assessment of mitral annulus velocity by Doppler tissue imaging in the annulus velocity by Doppler tissue imaging in the Cardiol 1997;30:474-80.

19 McDicken WN, Sutherland GR, Moran CM, et al. Colour Doppler velocity imaging of the myocardium. Ultrasound Med Biol 1992;18:651-4.

20 Miyatake K, Yamagishi M, Tanaka N, et al. New method for evaluating left ventricular wall motion by color-coded tissue Doppler imaging: in vitro and in vivo studies. $\mathcal{F} A m$ Coll Cardiol 1995;25:717-24.

21 Garcia MJ, Palac RT, Malenka DJ, et al. Color M-mode Doppler flow propagation velocity is a relatively preloadindependent index of left ventricular filling. F $\mathrm{Am}$ Soc Echocardiogr 1999;12:129-37.

22 Sagar KB, Hastillo A, Wolfgang TC, et al. Left ventricular mass by $\mathrm{M}$-mode echocardiography in cardiac transplant patients with acute rejection. Circulation 1981;64:II-21720 .

23 Puleo JA, Aranda JM, Weston MW, et al. Noninvasive detection of allograft rejection in heart transplant recipients by use of Doppler tissue imaging. F Heart Lung Transplant 1998; 17:176-84

24 Amende I, Simon R, Seegers A, et al. Diastolic dysfunction during acute cardiac allograft rejection. Circulation 1990; 81:III-66-70.

25 Latre JM, Arizon JM, Jimenez-Heffernan A, et al. Noninvasive radioisotopic diagnosis of acute heart rejection. F Heart Lung Transplant 1992;11:453-6; discussion 457.

26 Seiler C, de Marchi SF, Heule K. Doppler-diastologic carnival: false and correct unmasking of disturbed LV relaxation in individuals with normal transmitral flow velocity pattern [abstract]. Eur Heart f 1998;19(suppl): 548 .

27 de Marchi SF, Bodenmuller M, Lai DL, et al. Pulmonary venous flow velocity patterns in 404 individuals without cardiovascular disease. Heart 2001;85:23-9.

28 Hausmann B, Muurling S, Stauch C, et al. Detection of diastolic dysfunction: acoustic quantification (AQ) in comparison to Doppler echocardiography. Int $\mathcal{f}$ Card Imaging 1997; 13:301-10

29 Derumeaux G, Douillet R, Redonnet M, et al. Detection of acute rejection of heart transplantation by Doppler color acute rejection of heart transplantation by Doppler

30 Mankad S, Murali S, Kormos RL, et al. Evaluation of the potential role of color-coded tissue Doppler echocardiography in the detection of allograft rejection in heart transplant recipients. Am Heart $\mathcal{F}$ 1999;138:721-30.

\section{WEB TOP 10}

www.heartinl.com

These articles scored the most hits on Heart's web site during July 2001

1 Long term results of mechanical prostheses for treatment of active infective endocarditis fM Guerra, MP Tornos, G Permanyer-Miralda, $B$ Almirante, $M$ Murtra, $\mathcal{F}$ Soler-Soler

July $200186 ; 63-8$. (Interventional cardiology and surgery)

2 Implantable cardioverter-defibrillators DT Connelly

August 2001;86:221-6. (Education in Heart)

3 Management of pericardial effusion f Soler-Soler, 7 Sagrista-Sauleda, G PermanyerMiralda

August 2001;86:235-40. (Education in Heart)

4 Impact of diabetes mellitus on long term survival after acute myocardial infarction in patients with single vessel disease $M$ Ishihara, $H$ Sato, $T$ Kawagoe, Y Shimatani, $S$ Kurisu, K Nishioka, Y Kouno, $T$ Umemura, $S$ Nakamura

August 2001;86:133-8. (Cardiovascular medicine)

5 Matching the right drug to the right patient in essential hypertension MF Brown

July 2001:86:113-20. (Education in Heart)

6 Angiotensin receptor blockers for chronic heart failure and acute myocardial infarction

FFV McMurray

July 2001;86:97-103. (Education in Heart)

7 Joint British recommendations on prevention of coronary heart disease in clinical practice

December 1998;80(suppl 2):S1-29.

8 Diseases of the thoracic aorta

$R$ Erbel

August 2001;86:227-34. (Education in Heart)

9 Role of stenting in coronary revascularisation

AH Gershlick

July 2001;86:104-12. (Education in Heart)

10 Guideline for the management of patients with acute coronary syndromes without persistent ECG ST segment elevation February 2001;85:133-42.

Visit the Heart website for hyperlinks to these articles, by clicking on "Top 10 papers" www. heartinl.com 